\title{
Serological Relationships of Spiroplasmas as Shown by Combined Deformation and Metabolism Inhibition Tests
}

\author{
DAVID L. WILLIAMSON, ${ }^{1}$ JOSEPH G. TULLY, ${ }^{2}$ AND ROBERT F. WHITCOMB ${ }^{3}$
}

Department of Anatomical Sciences, State University of New York, Stony Brook, New York 11794;" Laboratory of Infectious Diseases, National Institute of Allergy and Infectious Diseases, National Institutes of Health, Bethesda, Maryland 20014; ${ }^{2}$ and Plant Protection Institute, Federal Research, Science and Education Administration, U.S. Department of Agriculture, Beltsville, Maryland $20705^{3}$

The deformation test and the metabolism inhibition test are simple and highly sensitive serological tests capable of revealing antigenic differences among spiroplasmas. Spiroplasma strains from plant and invertebrate hosts were compared in a combined deformation-metabolism inhibition test conducted in microtiter plates. Four major serological groups of spiroplasmas were recognized on the basis of deformation-metabolism inhibition tests. Group 1 was the Spiroplasma citri complex, comprised of isolates from plants, insects, and ticks. This group was provisionally divided into four serological subgroups. Subgroup 1 included the $S$. citri type strain (Maroc) and spiroplasmas isolated by Kondo and associates from cactus and lettuce. The second subgroup contained three corn stunt spiroplasma isolates. Subgroup 3 comprised 2 Spiroplasma strains isolated from honey bees by T. B. Clark. Subgroup 4 consisted of a single isolate $(277 \mathrm{~F})$ from ticks. Each of these subgroups showed some serological cross-reactions with one or more of the other subgroups. Three other serologically distinct Spiroplasma clusters were observed. The suckling mouse cataract agent and an additional rabbit tick isolate (TP-2) were placed in group 2. Group 3 spiroplasmas included T. B. Clark's isolates (OBMG and BNR1) from flowers of magnolia and tulip trees. The fourth distinct serological group was represented by the uncultivated sex ratio spiroplasmas from Drosophila.

The spiroplasmas are a recently recognized group of helical, highly motile mycoplasmas that have attracted increased attention from biologists because of their unusual features. In addition to their motility and unique morphology, spiroplasmas are associated with a variety of pathological conditions in both plants and animals. For example, a spiroplasma associated with citrus stubborn disease was described by Saglio et al. (11). Later, a spiroplasma-like organism was cultivated from corn plants infected with the stunt disease $(2,17)$. It is assumed that this organism and all other strains included in this study will eventually be recognized as $S p i$ roplasma strains, although the evidence required for establishment of the exact taxonomic position of the strains is not yet available. Spiroplasmas are maternally transmitted and induce lethality of male progeny in several related species of Drosophila $(10,16)$. Spiroplasmas are lethal agents in honey bees $(3,4)$ and occur on the surfaces of tree flowers; the latter agents are not known to be associated with any disease (4, 6). A tick-derived spiroplasma is able to kill chicken embryos and to cause cataracts, neurological disturbances, and death in experimental infections of suckling rats $(14,15 ; \mathrm{D}$. Stiller, R.
F. Whitcomb, and M. E. Coan, Abstr. Annu. Meet. Am. Soc. Microbiol. p. 72, G7, 1978).

Previous studies of relatedness among spiroplasmas have utilized one- and two-dimensional polyacrylamide gel electrophoretic patterns of cell proteins $(5,8,9,11)$ and serological procedures such as growth inhibition $(2,13,14,16)$ and complement fixation (14). However, with the exception of two-dimensional gel electrophoresis, these procedures lack sufficient sensitivity for separation of Spiroplasma strains.

The Spiroplasma deformation (DF) test (1618) has been shown to provide high homologous titers and thus possesses the level of sensitivity needed to separate Spiroplasma strains. Another serological procedure, the metabolic inhibition (MI) test (12), has been employed frequently with mycoplasmas but has had limited use with spiroplasmas $(2,6)$. In the present study we have combined the DF and MI tests by performing them in single microtiter plates.

\section{MATERIALS AND METHODS}

Spiroplasma strains and media. The designations and the sources of the spiroplasmas used in the combined DF/MI test are given in Table 1 . All cultures 
TABLE 1. Spiroplasma strains used in the combined DF/MI tests

\begin{tabular}{|c|c|c|c|c|}
\hline $\begin{array}{c}\text { Species } \\
\text { name or } \\
\text { group } \\
\text { designation }\end{array}$ & $\begin{array}{c}\text { Strain } \\
\text { designation }\end{array}$ & Host origin & ATTC no. & Reference \\
\hline \multirow[t]{3}{*}{ S. citri } & $\begin{array}{c}\text { Maroc (= R8A2) } \\
\text { (type strain) }\end{array}$ & Orange tree (stubborn disease) & 27556 & 11 \\
\hline & Cactus & Opuntia tuna & & $\begin{array}{l}\text { Kondo et al., } \\
1976\end{array}$ \\
\hline & Lettuce & Lettuce & 29594 & $\begin{array}{l}\text { Kondo et al., } \\
1977\end{array}$ \\
\hline \multirow[t]{3}{*}{ Corn stunt } & $\begin{array}{r}\text { Rio Grande } \\
(=\mathrm{E}-275)\end{array}$ & Corn (stunt disease) & 29320 & 17 \\
\hline & $\begin{array}{c}\text { Rio Grande } \\
(=\mathrm{I}-747)\end{array}$ & Corn (stunt disease) & 29051 & 2 \\
\hline & Mississippi E & Corn (stunt disease) & & 7 \\
\hline Tick group 1 & $\begin{array}{l}\text { SMCA } \\
\text { TP-2 }\end{array}$ & $\begin{array}{l}\text { Rabbit tick } \\
\text { Rabbit tick }\end{array}$ & 29335 & $\begin{array}{c}14,15 \\
\text { Stiller et al., } \\
1978\end{array}$ \\
\hline Tick group 2 & $277 \mathrm{~F}$ & Rabbit tick & 29761 & 1 \\
\hline \multirow[t]{2}{*}{ Honey bee } & $\mathrm{BC} 3$ & Honey bee & & 3 \\
\hline & KC3 & Honey bee & & 3 \\
\hline \multirow[t]{2}{*}{ Flower } & OBMG & Magnolia tree & & 4 \\
\hline & BNR1 & Tulip tree & & 4 \\
\hline
\end{tabular}

were grown in $100 \mathrm{ml}$ of M1A medium (7) at 30 or $32^{\circ} \mathrm{C}$. Cultures were monitored by dark-field microscopy to assure favorable morphology for conducting the DF test (18), and 3-ml portions were then frozen at $-70^{\circ} \mathrm{C}$. Frozen cultures were thawed at room temperature immediately before use. The M1A medium was used for diluting all spiroplasma and antiserum preparations.

Antisera. The procedures for antiserum production and subsequent handling have been described in detail in a previous publication (18). All antisera were heat inactivated at $56^{\circ} \mathrm{C}$ for $30 \mathrm{~min}$, filtered through $450-\mathrm{nm}$ membrane filters, and stored at $-20^{\circ} \mathrm{C}$ in $3-\mathrm{ml}$ vials.

Procedure for the combined DF/MI test. Preliminary titrations of each frozen antigen were performed (i) to determine the titer of the antigen suspension in color-changing units (CCU), where $1 \mathrm{CCU}$ is the highest 10 -fold dilution of the antigen that produced a color change (yellow) in M1A medium containing phenol red indicator within a specified period of time, and (ii) to determine the appropriate antigen dilutions for carrying out the DF and MI tests (see procedure for antigen titrations below).

All tests were performed in microtiter plates (BBL Microbiology Systems, Cockeysville, Md., or Cooke Laboratory Products, Alexandria, Va.). Each plate contained eight rows (A to $\mathrm{H}$ ) of 12 wells.

Stepwise procedure for antigen titrations. The stepwise procedure for antigen titrations was as follows.

Step 1. Frozen cell suspensions and antisera were removed from the freezer and allowed to thaw at room temperature.

Step 2. Spiroplasma antigens were prepared (in 3$\mathrm{ml}$ vials) in volumes sufficient to carry out the test (2 to $3 \mathrm{ml}$ ) to the following dilutions: undiluted, $1: 2,1: 4$, $10^{-1}, 10^{-2}, 10^{-3}, 10^{-4}$, and $10^{-5}$.

Step 3. Stock dilutions of antiserum were prepared separately in 3-ml vials. The serum was usually diluted
1:3 for heterologous tests or 1:81 for homologous tests. Step 4. Preparation of plates for tests was as follows.

(i) A 100- $\mu$ l amount of growth medium was added to test wells 1 to 9,11 , and 12 (antigen titration wells), and $150 \mu \mathrm{l}$ was added to well 10 (medium control well).

(ii) A 50- $\mu$ l amount of 1:81 antiserum dilution was placed in well 1 , rows $A$ to $H$, producing a 1:243 initial antiserum dilution in well 1.

(iii) By using 50- $\mu$ m microdiluters (Cooke Laboratory Products) threefold dilutions were made by mixing the antiserum in the first well and transferring $50 \mu \mathrm{l}$ serially through well 9.

(iv) A 50- $\mu$ l amount of each antigen suspension was added, one dilution for each row, beginning with row A, to wells 1 to 9,11 , and 12 .

(v) A 50- $\mu$ l amount of a guinea pig complement (Cappel Laboratories, Downingtown, $\mathrm{Pa}$.) solution in M1A medium was added to each well in all rows. Freeze-dried complement was rehydrated with phosphate-buffered saline and stored at $-70^{\circ} \mathrm{C}$ in 1.0 - or $1.5-\mathrm{ml}$ volumes. Before the test, $8 \%$ complement $(0.8$ $\mathrm{ml}$ of rehydrated complement plus $9.2 \mathrm{ml}$ of M1A medium) was prepared, passed through a sterile membrane filter $(450 \mathrm{~nm})$, and kept at 4 to $5^{\circ} \mathrm{C}$ until added to the test plate wells.

(vi) The plate was covered with a rigid plastic lid (Linbro Scientific, Inc., Hamden, Conn.) and allowed to incubate at room temperature for $30 \mathrm{~min}$ before beginning DF titer (18) determinations. DF titers were best determined when the number of spiroplasmas averaged 20 to 30 per $1,250 \times$ microscopic field. Antigen control wells containing undiluted, $1: 2,1: 4$, and in certain cases 1:10 dilutions were examined to find the dilution which provided the appropriate number of spiroplasmas. This dilution of frozen spiroplasmas was used in all tests (Table 2). Note that the final antiserum dilution in each well was doubled because of the addition of antigen $(50 \mu \mathrm{l})$ and complement solution $(50 \mu \mathrm{l})$. Table 3 shows the values of threefold antiserum dilutions in each of the nine wells of the microtiter 
TABLE 2. Titrations of frozen Spiroplasma cultures used in DF and MI tests

\begin{tabular}{|c|c|c|c|c|}
\hline $\begin{array}{l}\text { Spiroplasma } \\
\text { strain }\end{array}$ & $\begin{array}{c}\text { Frozen } \\
\text { antigen } \\
(\mathrm{CCU} / \mathrm{ml})\end{array}$ & $\begin{array}{l}\text { DF test } \\
\text { antigen } \\
\text { dilution }\end{array}$ & $\begin{array}{l}\text { MI test } \\
\text { antigen } \\
\text { dilution }\end{array}$ & $\begin{array}{c}\text { Day at } \\
\text { which } \\
\text { endpoint } \\
\text { read }\end{array}$ \\
\hline \multicolumn{5}{|l|}{ S. citri } \\
\hline Maroc & $10^{10}$ & $1: 2$ & $10^{-4}$ & 5 \\
\hline Cactus & $10^{9}$ & $1: 2$ & $10^{-2}$ & 3 \\
\hline Lettuce & $10^{8}$ & $1: 2$ & $10^{-2}$ & 5 \\
\hline \multicolumn{5}{|l|}{ Corn stunt } \\
\hline E-275 & $10^{9}$ & $1: 2$ & $10^{-1}$ & 5 \\
\hline I-747 & $10^{8}$ & Undiluted & $10^{-1}$ & 7 \\
\hline Mississippi E & $10^{6}$ & $1: 2$ & $10^{-1}$ & 5 \\
\hline \multicolumn{5}{|l|}{ Tick group 1} \\
\hline SMCA & $10^{10}$ & $1: 2$ & $10^{-2}$ & 7 \\
\hline TP-2 & & $1: 4$ & $10^{-2}$ & 5 \\
\hline \multicolumn{5}{|l|}{ Tick group 2} \\
\hline $277 \mathrm{~F}$ & $10^{9}$ & $1: 2$ & $10^{-2}$ & 4 \\
\hline \multicolumn{5}{|l|}{ Honey bee } \\
\hline BC3 & $10^{9}$ & $1: 4$ & $10^{-3}$ & 5 \\
\hline KC3 & $10^{9}$ & $1: 4$ & $10^{-3}$ & 4 \\
\hline \multicolumn{5}{|l|}{ Flower } \\
\hline OBMG & $10^{10}$ & $1: 4$ & $10^{-3}$ & 2 \\
\hline BNR1 & $10^{9}$ & $1: 2$ & $10^{-3}$ & 2 \\
\hline
\end{tabular}

TABLE 3. Values of threefold dilutions of antisera and their final dilution value after mixing components in the combined $D F / M I$ test

\begin{tabular}{ll}
\hline $\begin{array}{c}\text { Threefold } \\
\text { antiserum } \\
\text { dilutions }^{a}\end{array}$ & $\begin{array}{l}\text { Final dilution } \\
\text { of antiserum }^{b}\end{array}$ \\
\hline $1: 3$ & $1: 6$ \\
$1: 9$ & $1: 18$ \\
$1: 27$ & $1: 54$ \\
$1: 81$ & $1: 162$ \\
$1: 243$ & $1: 486$ \\
$1: 729$ & $1: 1,458$ \\
$1: 2,187$ & $1: 4,374$ \\
$1: 6,551$ & $1: 13,102$ \\
$1: 19,653$ & $1: 39,306$ \\
$1: 58,959$ & $1: 117,918$ \\
$1: 176,877$ & $1: 353,754$ \\
$1: 530,631$ & $1: 1,061,262$ \\
$1: 1,591,893$ & $1: 3,183,786$ \\
\hline
\end{tabular}

${ }^{a}$ Medium ( $\left.100 \mu \mathrm{l}\right)$ plus antiserum $(50 \mu \mathrm{l})$.

${ }^{b}$ After addition of Spiroplasma $(50 \mu \mathrm{l})$ and complement $(50 \mu \mathrm{l})$.

plate and the final dilution of antiserum after adding the spiroplasma suspension and the complement solution to each well.

(vii) After DF titer determinations were made, the plate was sealed with Pressure Sensitive Film (Falcon Plastics, Los Angeles, Calif.) and incubated at $30^{\circ} \mathrm{C}$. (a) The plate was read daily over a test-reading mirror, and the $\mathrm{pH}$ shift from red to yellow (1 to $1.5 \mathrm{pH}$ units) was observed in wells 11 and 12 , rows $A$ to $H$. The highest dilution of antigen giving a color change indi- cated the number of CCU per $50 \mu \mathrm{l}$. (b) When the number of antigen control wells showing change had stabilized ( 4 to 9 days), the $\mathrm{pH}$ change in wells 1 to 9 , rows $A$ to $H$, was read. The MI titer of the antiserum for each antigen dilution was defined as the reciprocal of the highest antiserum dilution that prevented color change. For subsequent MI tests with this frozen spiroplasma, the dilution used was that which provided 10 to $1,000 \mathrm{CCU}$ per $50 \mu \mathrm{l}$ and which also had the highest MI titer (12). The appropriate DF and MI dilutions and the time for reading the MI test were recorded and kept with vials of each frozen Spiroplasma antigen (Table 2).

Homologous and heterologous test procedures. DF/MI tests were performed in which single spiroplasmas were tested in homologous combination against their specific antisera and in heterologous combinations against each of the other Spiroplasma antisera. The antigen dilutions used for the DF and the MI tests were those previously determined in the antigen titrations. The heterologous DF/MI tests for each Spiroplasma strain were completed in a single run if possible. Fresh vials of frozen cell suspensions were used in subsequent tests, but the use of frozen suspensions permitted the elimination of homologous tests in continued testing of each Spiroplasma strain.

Step 1. Two rows of wells were used to test the spiroplasmas against each antiserum: the first row was used for the DF test and the second was used for the MI test.

Step 2. For each antiserum, $100 \mu \mathrm{l}$ of M1A medium was added to wells 1 to 9,11 , and 12 , and $150 \mu \mathrm{l}$ was added to well 10.

Step 3. For homologous tests, $50 \mu \mathrm{l}$ of a 1:81 antiserum stock dilution was added to the $100 \mu \mathrm{l}$ of medium in well 1 in both the DF and MI test rows. Threefold 
dilutions were then made, with $50-\mu$ microdiluters, in wells 1 to 9 .

Step 4. For heterologous tests, $50 \mu \mathrm{l}$ of a $1: 3$ stock dilution for each antiserum being tested was added to the $100 \mu \mathrm{l}$ of medium in well 1 in both the DF and MI test rows. Threefold dilutions were then made, with $50-\mu$ l microdiluters, in wells 1 to 9 .

Step 5. A 50- $\mu$ l amount of cell suspension at the dilution previously determined for the DF and MI tests was added in the appropriate rows to wells 1 to 9,11 , and 12 .

Step 6. A $50-\mu \mathrm{l}$ amount of $8 \%$ guinea pig complement solution was added to each well in all rows.

Step 7. The plate was covered with a rigid plastic lid and incubated for $30 \mathrm{~min}$ at room temperature.

Step 8. Deformation titers were determined as previously described (18).

Step 9. The plate was sealed with Pressure Sensitive Film and incubated at $30^{\circ} \mathrm{C}$.

Step 10. MI titers were read on the day which had been previously determined to be optimum for the Spiroplasma strain being tested.

\section{RESULTS AND DISCUSSION}

Frozen antigen titrations. An example of a homologous DF/MI antigen titration following the procedures outlined above is illustrated in Fig. 1, in which a frozen culture of the Mississippi E strain of the corn stunt spiroplasma was titrated (see procedure for antigen titrations, step $4, \mathrm{i}$ to $\mathrm{v}$ ). The dark wells are those in which there was no change in the phenol red $\mathrm{pH}$ indicator; the light wells are those in which the indicator changed to yellow (acid) as a result of corn stunt spiroplasma growth and metabolism. The plate is shown as it appeared 8 days after

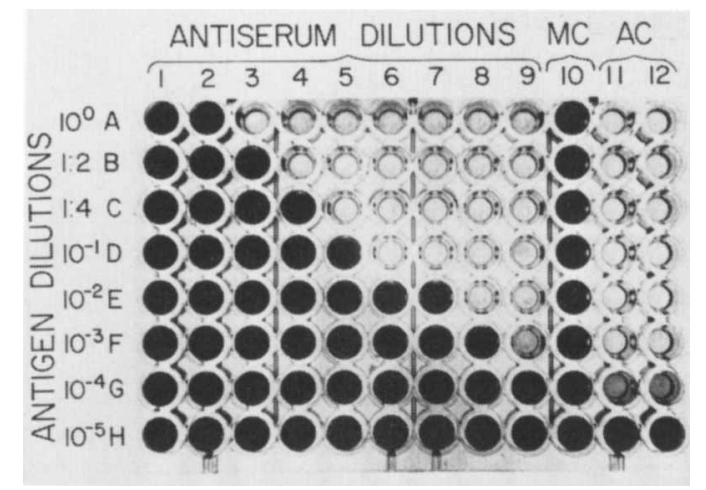

FIG. 1. Microtiter plate showing results of homologous DF/MI titration of frozen Mississippi $E$ strain of corn stunt spiroplasma. See text for antigen and antiserum dilutions. Dark wells contain medium of red color ( $\mathrm{pH} \sim 7.6)$; wells which appear colorless contain medium of yellow color ( $p H \sim 6.5)$. Photographed on day 8 of incubation at $30^{\circ} \mathrm{C}$. MC, medium control wells; $A C$, antigen control wells. addition of materials. Rows $A$ and $B$ were used for DF titer determinations. DF titers for the undiluted (A) and the 1:2 (B) dilution of the frozen cell suspension were 4,374 (well 3 ) and 13,102 (well 4), respectively. Metabolic inhibition (dark wells in Fig. 1) was observed in rows A (wells 1 and 2) and B (wells 1 to 3), giving MI titers of 1,458 for undiluted antigen and 4,374 for the 1:2 antigen dilution. Both titers are one threefold dilution lower then the corresponding DF titers. This difference in DF and MI titers is explained by the definition of the DF titer (as containing one-half deformed and one-half unaffected cells). The growth of unaffected cells causes the color change in the DF titer well. The $1: 4$ antigen dilution employed in row $\mathrm{C}$ was judged to contain too few cells for a DF test; thus, rows $\mathrm{C}$ to $\mathrm{H}$ were used only for MI titer determinations.

A striking positive correlation was demonstrated between antigen concentration and MI endpoint dilution of the antiserum. A relationship between Spiroplasma antigen concentration and antiserum titer has been observed previously in DF titer determinations (18). The MI titers for rows $\mathrm{C}$ to $\mathrm{F}$ can be easily determined in this plate (Fig. 1) by noting the highest antiserum dilution well in which there was no color change. In rows $\mathrm{G}$ and $\mathrm{H}$, antigen dilutions $10^{-4}$ and $10^{-5}$, respectively, the available antibody prevented the growth and metabolism of the cells, at least through day 8 . The dilution of antiserum at these cell dilutions was equal to or greater than $3 \times 10^{-6}$. Cells must have been present in row $\mathrm{G}$ since a color change in the antigen control wells was observed (row G, wells 11 and 12). However, the antigen dilution $\left(10^{-5}\right)$ in row $\mathrm{H}$ exceeded the number of $\mathrm{CCU}$ in this frozen antigen suspension. A titration of each of the frozen Spiroplasma strains used in the DF/ MI tests reported here was made as described above (Table 2).

Requirement for complement in the DF/ MI test. A requirement for complement in the MI tests of some mycoplasmas has been previously demonstrated (12). In our report on the Spiroplasma DF test (18), the addition of guinea pig complement at a final concentration of $2 \%$ to the antigen-antibody mixture had no effect on the Spiroplasma DF titer. By using heated $\left(56^{\circ} \mathrm{C}\right.$ for $\left.30 \mathrm{~min}\right)$ antiserum and adding heatinactivated guinea pig complement to the antigen antibody mixture, we found that completely deformed cells at high antigen concentrations (1:2 and 1:4) were able to metabolize and produce a color change in the test wells. That the color change observed was not due to multiplication of cells was suggested by the absence of helical forms and was confirmed by failure to establish subcultures from wells containing only 
deformed cells. Thus, in the presence of inactivated complement, deformed cells were capable of metabolism but could not multiply. Both metabolism and multiplication of deformed cells was inhibited in the presence of unheated complement.

Spiroplasma groups. Heterologous tests were normally performed as illustrated in Fig. 2. Frozen corn stunt spiroplasma antigen (E-275 strain) was tested at dilutions of $1: 2$ in the DF test (row A) and at $10^{-1}$ in the MI test (row B) against homologous antiserum. In addition, the same antigen dilutions were tested against heterologous antisera to Spiroplasma citri (rows D and E) and suckling mouse cataract agent (SMCA) spiroplasmas (rows G and $\mathrm{H}$ ). The dilution of antiserum in well 1 was 1:243 for homologous antiserum and 1:6 for both $S$. citri and SMCA antisera. The DF titers were 4,374 against homologous antiserum, 162 against $S$. citri antiserum, and less than 6 against SMCA antiserum. All spiroplasmas employed in this comparative study were tested in the same fashion in the combined DF/MI test, except that the antiserum dilution in well number 1 was 1:486 for homologous antisera and 1:18 for heterologous antisera.

Results of representative DF/MI tests are pre-

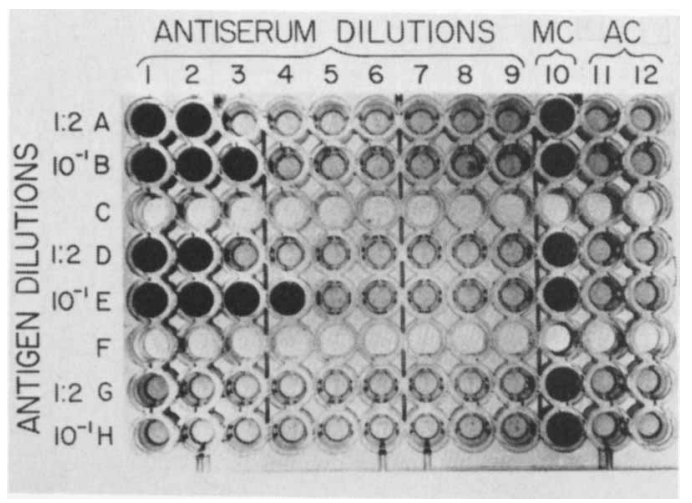

FIG. 2. Microtiter plate showing E-275 strain of corn stunt spiroplasma in homologous $D F / M I$ tests (rows $A$ and $B$ ) and in heterologous tests against $S$. citri (rows $D$ and $E$ ) and SMCA (rows $G$ and $H$ ) antisera. See text for antigen and antiserum dilutions. Color of wells as for Fig. 1. Photographed on eighth day of incubation at $30^{\circ} \mathrm{C} . \mathrm{MC}$, medium control wells; $A C$, antigen control wells. sented in Tables 4, 5, and 6. In Table 4, the results of tests are shown that involve the type strain (Maroc) of $S$. citri and spiroplasmas derived from lettuce ( $\mathrm{F}$. Kondo, $\mathrm{K}$. Maramorosch, A. H. McIntosh, and E. H. Varney, Proc. Am. Phytopathol. Soc., 1977, p. 190-191) and the ornamental cactus Opuntia tuna monstrosa (F. Kondo, A. H. McIntosh, S. B. Padhi, and K. Maramarosch, Proc. Soc. Gen. Microbiol., 1976, p. 154). The close relationship between the DF and MI titers among these three spiroplasmas demonstrates that the lettuce and cactus spiroplasmas are serologically indistinguishable from $S$. citri. Likewise, the three isolates of the Rio Grande corn stunt spiroplasma are indistinguishable by $\mathrm{DF} / \mathrm{MI}$ tests (Table 5).

In Table 6 we have compared reciprocal DF/ MI titers of S. citri, the E-275 strain of the corn stunt spiroplasma, and representative isolates of other available spiroplasmas. The results of these comparisons indicate that there are presently four major serological groups of spiroplasmas that can be separated on the basis of DF/ MI tests. The first major group, the $S$. citri complex, contains spiroplasmas that show serological cross-reactions at varying levels with members of four subgroups: subgroup 1 contains the type strain (Maroc) of $S$. citri and spiroplasmas that were isolated from cactus and lettuce. This group shares some antigens with the spiroplasmas of corn stunt, the tick-derived $277 \mathrm{~F}$ spiroplasma, and a spiroplasma from the honey bee (BC 3 strain).

Subgroup 2 contains Spiroplasma strains (E275, I-747, Mississippi E) isolated from corn plants affected with corn stunt disease. These isolates are also obviously closely related to each other. They not only share some antigens in reciprocal tests with subgroup 1 spiroplasmas but also have antigens in common with $277 \mathrm{~F}$ and BC3.

Subgroup 3 contains two Spiroplasma strains (BC3 and KC3) isolated by T. B. Clark from honey bees. Only the results with the BC3 strain are shown here since the KC3 showed complete identity in DF/MI titers with BC3 antiserum. These spiroplasmas also show broad reciprocal sharing of antigens with subgroups 1 and 2 and with subgroup $4(277 \mathrm{~F})$. There is also a low-level one-way cross-reaction between honey bee spiroplasmas and antisera prepared against the

TABLE 4. Homologous DF/MI titers for S. citri strains

\begin{tabular}{lccc}
\hline \multirow{2}{*}{ Antigens } & \multicolumn{3}{c}{ Antiserum $^{a}$ to $S$. citri strains } \\
\cline { 2 - 4 } & Maroc & Cactus & Lettuce \\
\hline Maroc & $13,102 / 353,754$ & $13,102 / 1,061,262$ & $4,374 / 1,061,262$ \\
Cactus & $13,102 / 353,754$ & $13,102 / 117,918$ & $4,374 / 13,102$ \\
Lettuce & $39,306 / 353,754$ & $13,102 / 117,918$ & $39,306 / 117,918$ \\
\hline
\end{tabular}

${ }^{a}$ Titers are given as a fraction, DF/MI. 
TABLE 5. Homologous DF/MI titers for corn stunt Spiroplasma strains

\begin{tabular}{lcc}
\hline \multirow{2}{*}{ Antigens } & \multicolumn{2}{c}{$\begin{array}{c}\text { Antiserum } \\
\text { stunt spiroplasmas }\end{array}$} \\
\cline { 2 - 3 } & $\mathbf{E}-275$ & Mississippi $\mathbf{E}$ \\
\hline E-275 & $39,306 / 1,061,262$ & $4,374 / 39,306$ \\
$\mathrm{I}-747^{b}$ & $117,918 / 117,918$ & $117,918 / 117,918$ \\
Mississippi E & $39,306 / 117,918$ & $39,306 / 117,918$ \\
\hline${ }^{a}$ Titers are given as a fraction, DF/MI. \\
${ }^{b}$ Antiserum to strain I-747 not available for testing.
\end{tabular}

flower spiroplasmas (OBMG and BNR1). The significance of this one-way reaction is not understood.

Subgroup 4 has only a single strain, the tick group 2 spiroplasma $(277 \mathrm{~F})$ isolated from the rabbit tick. This organism shows close relationship with subgroup 2 (corn stunt) and, to a lesser degree, with subgroup 3 (honey bee). It is noteworthy that $277 \mathrm{~F}$ appears to be unrelated to the other rabbit tick isolates (SMCA and TP-2).

The tick group 1 spiroplasmas, SMCA and TP-2, comprise the second major serological group. These spiroplasmas share very few antigens with most spiroplasmas, although TP-2 appears to have a low-level relationship with the flower isolates.

The third major serological group contains ' $T$. B. Clark's OBMG and BNR1 strains recovered from flowers of the magnolia and tulip tree, respectively. These spiroplasmas appear to exhibit no serological relationships in either DF or MI tests to any of the other spiroplasma antisera available. The minimal relationships observed between these organisms and $S$. citri subgroup 3 (honey bee), the TP-2 tick spiroplasmas, and the flower spiroplasmas were expressed as oneway cross-reactions.

The fourth serological group is represented by the sex ratio spiroplasmas from Drosophila. Since these organisms have not yet been grown in culture, they could be tested only by the DF test. Except for a one-way cross-reaction with antiserum against the E-275 strain of corn stunt, the sex ratio spirosplasmas used in these tests do not show any significant cross-reaction with any of the antisera tested.

During the preparation of this manuscript, a report (6a) was submitted which established three serological Spiroplasma groups: an S. citri group and two groups from flowers. The correspondence of these groups to the groups outlined in this paper is unclear since the isolates on which the three groups were established were not available to us. Comprehensive comparisons of the various strains will be required to link the results of the two studies.

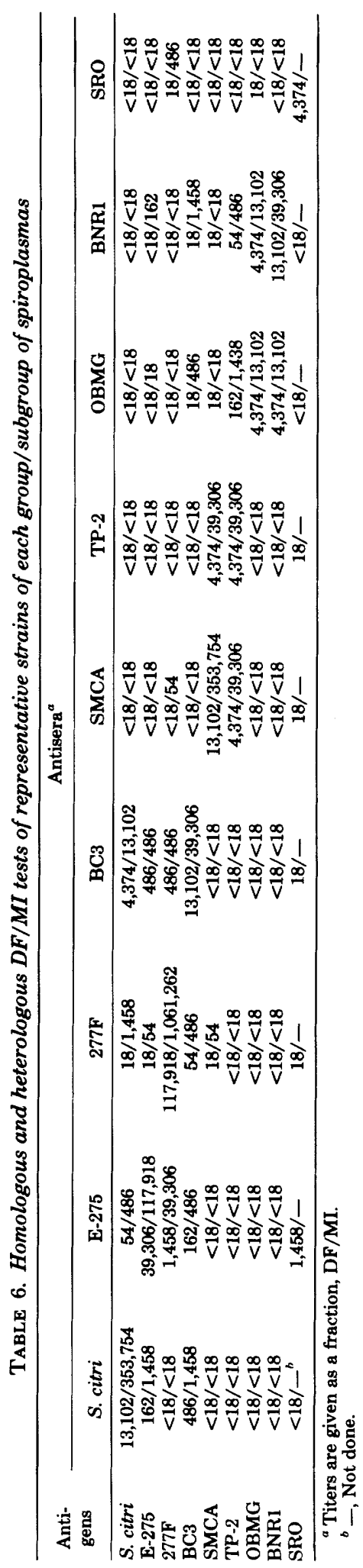


The DF and MI tests are sensitive serological tests for elucidating relationships among spiroplasmas, and results from the two tests are closely correlated. The most obvious advantage of the DF test is its rapidity: titers can be determined 30 min after mixing antigen and antibody. However, a dark-field microscope is required for endpoint determinations. In contrast, the MI test requires little in the way of equipment (microtiter plates and diluters), but requires an incubation period of 3 to 10 days before results can be read. The procedures set forth in this paper simplify the performance of the DF test, through the use of microtiter plates, as compared with the tube method previously described (18). The addition of a standardized procedure for the MI test with spiroplasmas offers important advantages, since data from the two serological tests can be obtained in a single test run.

\section{ACKNOWLEDGMENTS}

This study was done in the laboratory of R. M. Cole, Laboratory of Streptococcal Diseases, National Institute of Allergy and Infectious Diseases, while D.L.W. was on sabbatical leave from the State University of New York at Stony Brook, under an Assignment Agreement, Title IV of the Intergovernmental Personnel Act.

We thank Truman B. Clark, Bioenvironmental Bee Laboratory, Plant Protection Institute, Federal Research, Science and Education Administration, U. S. Department of Agriculture, for making available to us Spiroplasma strains from bees and flowers. We also thank David Rose and Colis Blood for technical assistance during this study.

\section{REPRINT REQUESTS}

Address reprint requests to: Dr. D. L. Williamson, Department of Anatomical Sciences, Health Sciences Center, State University. of New York at Stony Brook, Stony Brook, NY 11794

\section{LITERATURE CITED}

1. Brinton, L. P., and W. Burgdorfer. 1976. Cellular and subcellular organization of the $277 \mathrm{~F}$ agent: a spiroplasma from the rabbit tick Haemaphysalis leporispalustris (Acari: Ixodidae). Int. J. Syst. Bacteriol. 26:554560.

2. Chen, T. A., and C. H. Liao. 1975. Corn stunt spiroplasma: isolation, cultivation, and proof of pathogenicity. Science 188:1015-1017.
3. Clark, T. B. 1977. Spiroplasma sp., a new pathogen in honey bees. Invertebr. Pathol. 29:112-113.

4. Clark, T. B. 1978. Honey bee spiroplasmosis, a new problem for beekeepers. Am. Bee J. 118:18-23.

5. Daniels, M. J., and B. M. Meddins. 1973. Polyacrylamide gel electrophoresis of mycoplasma proteins in sodium-dodecyl-sulfate. J. Gen. Microbiol. 76:239-242.

6. Davis, R. E. 1978. Spiroplasma associated with flowers of the tulip tree (Liriodendron tulipifera L.). Can. J. Microbiol. 24:954-959.

6a. Davis, R. E., I. M. Lee, and L. K. Basciano. 1979. Spiroplasma: serological grouping of strains associated with plants and insects. Can. J. Microbiol. 25: 861-866.

7. Jones, A. L., R. F. Whitcomb, D. L. Williamson, and M. E. Coan. 1977. Comparative growth and primary isolation of spiroplasmas in media based on insect tissue culture formulations. Phytopathology 67:738-746.

8. Mouches, C., J. C. Vignault, J. G. Tully, R. F. Whitcomb, and J. M. Bové. 1979. Characterization of spiroplasmas by one and two dimensional protein analysis on polyacrylamide slab gels. Curr. Microbiol. 2:69-74.

9: Padhi, S. B., A. H. McIntosh, and K. Maramorosch. 1977. Charaterization and identification of spiroplasmas by polyacrylamide gel electrophoresis. Phytopathol. Z. 90:268-272.

10. Poulson, D. F., and B. Sakaguchi, 1961. Nature of "sexratio" agent in Drosophila. Science 133:1489-1490.

11. Saglio, P., M.L'hospital, D. Laflèche, G. Dupont, J. M. Bové, J. G. Tully, and E. A. Freundt. 1973. Spiroplasma citri gen. and sp. n.: a mycoplasma-like organism associated with "stubborn" disease of citrus. Int. J. Syst. Bacteriol. 23:191-204.

12. Taylor-Robinson, D., R. H. Purcell, D. C. Wong, and R. M. Chanock. 1966. A colour test for the measurement of antibody to certain mycoplasma species based upon the inhibition of acid production. J. Hyg. 64:91104.

13. Tully, J. G., R. F. Whitcomb, J. M. Bové, and P. Saglio. 1973. Plant mycoplasmas: serological relation between agents asociated with citrus stubborn and corn stunt diseases. Science 182:827-829.

14. Tully, J. G., R. F. Whitcomb, H F. Clark, and D. L. Williamson. 1977. Pathogenic mycoplasmas: cultivation and vertebrate pathogenicity of a new spiroplasma. Science 195:892-894.

15. Tully, J. G., R. F. Whitcomb, D. L. Williamson, and H F. Clark. 1976. Suckling mouse cataract agent is a helical wall-free prokaryote (spiroplasma) pathogenic for vertebrates. Nature (London) 259:117-120.

16. Williamson, D. L., and R. F. Whitcomb. 1974. Helical, wall-free prokaryotes in Drosophila, leafhoppers and plants. Colloq. Inst. Nat. Santé Rech. Méd. 33:283-290.

17. Williamson, D. L., and R. F. Whitcomb. 1975. Plant mycoplasmas: A cultivable spiroplasma causes corn stunt disease. Science 188:1018-1020.

18. Williamson, D. L., R. F. Whitcomb, and J. G. Tully, 1978. The spiroplasma deformation test, a new serological method. Curr. Microbiol. 1:203-207. 